\title{
Determinants of trabecular bone score and prevalent vertebral fractures in women with fragility fractures: a cross-sectional sub-study of NoFRACT
}

\author{
T.T. Borgen ${ }^{1,2}$ (1) • Å. Bjørnerem ${ }^{3,4} \cdot$ L.B. Solberg ${ }^{5} \cdot$ C. Andreasen ${ }^{3,6} \cdot$ C. Brunborg ${ }^{7} \cdot$ M.-B. Stenbro ${ }^{1} \cdot$ L.M. Hübschle ${ }^{8}$.

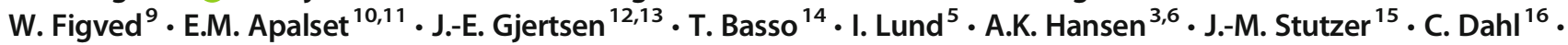 \\ L. Nordsletten ${ }^{2,5} \cdot$ F. Frihagen $^{5}$ - E.F. Eriksen ${ }^{2,17}$
}

Received: 5 September 2019 / Accepted: 28 October 2019 / Published online: 21 November 2019

(C) The Author(s) 2019

\begin{abstract}
Summary Determinants of trabecular bone score (TBS) and vertebral fractures assessed semiquantitatively (SQ1-SQ3) were studied in 496 women with fragility fractures. TBS was associated with age, parental hip fracture, alcohol intake and BMD, not SQ1-SQ3 fractures. SQ1-SQ3 fractures were associated with age, prior fractures, and lumbar spine BMD, but not TBS.

Introduction Trabecular bone score (TBS) and vertebral fractures assessed by semiquantitative method (SQ1-SQ3) seem to reflect different aspects of bone strength. We therefore sought to explore the determinants of and the associations between TBS and SQ1-SQ3 fractures.

Methods This cross-sectional sub-study of the Norwegian Capture the Fracture Initiative included 496 women aged $\geq 50$ years with fragility fractures. All responded to a questionnaire about risk factors for fracture, had bone mineral density (BMD) of femoral neck and/or lumbar spine assessed, TBS calculated, and 423 had SQ1-SQ3 fracture assessed.

Results Mean (SD) age was 65.6 years (8.6), mean TBS $1.27(0.10)$, and 33.3\% exhibited SQ1-SQ3 fractures. In multiple variable analysis, higher age $\left(\beta_{\text {per SD }}=-0.26,95 \% \mathrm{CI}:-0.36,-0.15\right)$, parental hip fracture $(\beta=-0.29,95 \% \mathrm{CI}:-0.54,-0.05)$, and daily alcohol intake $(\beta=-0.43,95 \% \mathrm{CI}-0.79,-0.08)$ were associated with lower TBS. Higher BMD of femoral neck $\left(\beta_{\text {per }}\right.$ $\mathrm{SD}=0.34,95 \%$ CI $0.25-0.43)$ and lumbar spine $\left(\beta_{\text {per SD }}=0.40,95 \%\right.$ CI $\left.0.31-0.48\right)$ were associated with higher TBS. In multivariable logistic regression analyses, age $\left(\mathrm{OR}_{\mathrm{per} S \mathrm{SD}}=1.94,95 \% \mathrm{CI} 1.51-2.46\right)$ and prior fragility fractures $(\mathrm{OR}=1.71,95 \%$ CI 1.09-2.71) were positively associated with SQ1-SQ3 fractures, while lumbar spine BMD $\left(\mathrm{OR}_{\mathrm{per}} \mathrm{SD}=0.7595 \%\right.$ CI 0.60
\end{abstract}

T.T. Borgen

tove.tveitan.borgen@vestreviken.no

1 Department of Rheumatology, Vestre Viken Hospital Trust, Drammen Hospital, Box 800, 3004 Drammen, Norway

2 Department of Clinical Medicine, University of Oslo, Oslo, Norway

3 Department of Clinical Medicine, UiT - The Arctic University of Norway, Tromsø, Norway

4 Department of Obstetrics and Gynecology, University Hospital of North Norway, Tromsø, Norway

5 Division of Orthopedic Surgery, Oslo University Hospital, Oslo, Norway

6 Department of Orthopedic Surgery, University Hospital of North Norway, Tromsø, Norway

7 Oslo Centre for Biostatistics and Epidemiology, Research Support Services, Oslo University Hospital, Oslo, Norway

8 Department of Orthopedic Surgery, Vestre Viken Hospital Trust, Drammen Hospital, Drammen, Norway
9 Department of Orthopedic Surgery, Vestre Viken Hospital Trust, Bærum Hospital, Bærum, Norway

10 Bergen group of Epidemiology and Biomarkers in Rheumatic Disease, Department of Rheumatology, Haukeland University Hospital, Bergen, Norway

11 Department of Global Public Health and Primary Care, University of Bergen, Bergen, Norway

12 Department of Orthopedic Surgery, Haukeland University Hospital, Bergen, Norway

13 Department of Clinical Medicine, University of Bergen, Bergen, Norway

14 Department of Orthopedic Surgery, St. Olavs University Hospital, Trondheim, Norway

15 Department of Orthopedic Surgery, Møre and Romsdal Hospital Trust, Molde Hospital, Molde, Norway

16 Department of Community Medicine and Global health, Institute of Health and Society, University of Oslo, Oslo, Norway

17 Department of Endocrinology, Morbid Obesity and Preventive Medicine, Oslo University Hospital, Oslo, Norway 
0.95) was negatively associated with SQ1-SQ3 fractures. No association between TBS and SQ1-SQ3 fractures was found. Conclusion Since TBS and SQ1-SQ3 fractures were not associated, they may act as independent risk factors, justifying the use of both in post-fracture risk assessment.

Keywords Bone mineral density $\cdot$ Fracture risk $\cdot$ Osteoporosis $\cdot$ Trabecular bone score $\cdot$ Vertebral fracture assessment $\cdot$ Vertebral fractures

\section{Introduction}

In recent years, trabecular bone score (TBS) and vertebral fracture assessment (VFA) have become established methods in clinical use, providing supplemental information on bone strength and future fracture risk [1-3]. Identification of the determinants of these indices is important for further understanding the pathophysiology of fracture risk and for identification of modifiable factors to prevent future fractures.

TBS is a grey-level textural index of trabecular bone microarchitecture obtained from dual-energy absorptiometry (DXA) images of the lumbar spine [4]. It is, however, still subject to discussion, which bone properties TBS actually reflects [5]. TBS predicts fragility fractures independently of bone mineral density (BMD) [2, 6-8]. The use of TBS for adjustment of 10-year probability of a hip or other major osteoporotic fracture (MOF) calculated by the Fracture Risk Assessment Tool (FRAX) is endorsed [9]. The retrospective Manitoba study is the largest study on determinants of TBS ( $n=29,407$ women)[10]. They found that TBS was negatively associated with glucocorticoid use, prior major fracture, rheumatoid arthritis, chronic obstructive pulmonary disease, high alcohol intake and higher body mass index (BMI) and positively associated with femoral neck and lumbar spine BMD, and $7-11 \%$ of the variation in TBS was explained by BMD [10]. Genetic factors explained approximately $45 \%$ of the variance in TBS in healthy Vietnamese subjects, whereas sex, age, and height accounted for about $28 \%$ of the total variance in TBS [11].

The presence of a vertebral fracture doubles the risk of subsequent fracture at any given BMD [12]. VFA of lateral spine $\mathrm{x}$-rays is therefore recommended as a part of the post-fracture risk assessment [13]. With higher resolution and image quality of modern DXA equipment, VFA of spine images obtained by DXA has become easily available and provides reliable information on vertebral fracture status in the thoracolumbar spine (T4-L4) at a much lower radiation dose compared to conventional lateral spine $\mathrm{x}$-rays. Determinants as age, BMD, height loss, and prior non-vertebral fractures are associated with prevalent vertebral fractures in a large population-based cohort study [14]. In the Rotterdam Study, incident vertebral fractures were reported to be strongly associated with prevalent vertebral fractures, early menopause, current smoking, use of walking aids, and low BMD [15]. In addition, the population-based European Prospective Osteoporosis Study (EPOS) showed that low BMD, low $\mathrm{BMI}$, and late menarche were associated with higher incidence of vertebral fractures while use of hormonal replacement therapy (HRT) was protective [16]. No associations between lifestyle factors such as smoking, alcohol intake, physical activity, or milk consumption and incident vertebral fracture were found in that study. A heritability of vertebral fractures (vertebral height reduction > $25 \%$ ) of more than $43 \%$ has been demonstrated [17].

Studies on the association between TBS and vertebral fractures diverge. Low TBS has been shown to be associated with a higher prevalence of vertebral fractures on VFA in women [18, 19], but there are also studies contradicting this notion [20]. In the prospective Manitoba study, TBS was associated with incident vertebral fractures in women but not in men [21]. Moreover, TBS was not associated with incident vertebral fractures in the men in the MrOs study [22]. In a previous publication of results from this sub-study of Norwegian Capture the Fracture Initiative (NoFRACT), we reported that more than half of the patients who had sustained a fragility fracture exhibited low TBS $(\leq 1.23)$, prevalent fracture on VFA or both [23]. Only $14 \%$ of these patients exhibited osteoporosis at the femoral neck, which increased to $28 \%$ when using the site with lowest BMD T-score. In the patients with osteopenia at the femoral neck, 34\% exhibited low TBS, 33\% vertebral fracture on VFA, but only $13 \%$ exhibited both low TBS and prevalent vertebral fracture. This is suggesting that TBS and VFA captured different aspects of bone strength. To better understand the potential pathophysiology underlying this diversity, identification of the determinants of both traits in the same cohort is of interest. Keeping in mind that heritability is a major determinant, investigation of clinical phenotypes and modifiable environmental risk factors may enable identification and treatment of individuals at risk. To our knowledge, this has not been studied in individuals with fractures. The objectives of this study were therefore (i) to explore the determinants of TBS and prevalent vertebral fractures on VFA, (ii) to explore whether prevalent vertebral fractures are determinants of TBS, and (iii) to explore whether TBS is a determinant of vertebral fractures in a cohort of women with fragility fractures. 


\section{Material and methods}

\section{Study subjects}

NoFRACT is a multicenter study at seven hospitals in Norway with 34,976 persons with fragility fractures enrolled by Jan 2019 [24]. The main aim is to investigate the effect of introducing a standardized intervention program consisting of a Fracture Liaison Service model of care for identification, assessment, and treatment of osteoporosis in patients with fragility fractures on the rate of subsequent fractures. Both women and men aged 50 years and older, who have recently sustained a clinical fragility fracture, are eligible to the intervention, with the exception of patients with fracture in fingers, toes, skull, and face.

This cross-sectional sub-study (NCT02608801) of NoFRACT (NCT02536898) included patients at the University Hospital of North Norway, Tromsø, from 1 Oct 2015 to 31 Dec 2017 and at Drammen Hospital in the south-eastern part of Norway from 1 Jan 2016 to 31 Dec 2017 [23, 25]. Of all patients of 50 years of age and above, attending to these hospitals with a fragility fracture, more than 90\% $(n=2682)$ were identified and offered fracture risk assessment. For elderly in-patients with fractures of hip, vertebrae, a total of two or more fragility fractures, or 10 -year probability of $\mathrm{MOF} \geq 20 \%$ calculated using FRAX, the treatment decision was made without the need of DXA scan $(n=1235)$. The participants were recruited among those who were referred to DXA $(n=$ 1447), of whom 839 consented to participate in the study, 675 women and 164 men [23]. We included a total of 496 women who all had responded to a questionnaire on risk factors for fracture, had valid measurement of TBS, and BMD of the femoral neck and lumbar spine, and 423 of them had VFA performed. No patients were excluded due to conditions known to affect bone metabolism, such as chronic kidney disease, use of anti-osteoporosis drugs, HRT, or premenopausal status. The study was approved by The Regional Committee for Medical and Health Research Ethics (REK 2014/2260).

\section{Variables}

The index fractures leading to inclusion were fragility fractures of the forearm $(n=196)$, ankle $(n=90)$, proximal humerus ( $n=68)$, hip ( $n=36)$, vertebrae (thoracic and lumbar) $(n=23)$, and other sites $(n=83)$. No women had rib or cervical fractures as index fracture. The vertebral fractures that led to inclusion were diagnosed on x-ray, CT, or MRI, not by VFA. Information on number of fractures after the age of 50, number of falls during the last 12 months before inclusion, parental history of hip fractures (yes vs. no), comorbidity, medication, postmenopausal status (yes vs. no), age at menopause, number of children, total months of breastfeeding, smoking (yes vs. no), daily alcohol intake (yes vs. no), physical activity (h/week), and dairy products (units/day) were collected through a questionnaire.

Height and weight was measured without shoes and heavy clothing, and BMI was calculated as weight per square meter height. BMD was measured at the lumbar spine (L1-L4), femoral neck, and total hip at both sides and using DXA Prodigy Pro in Tromsø and iDXA Pro in Drammen (both GE Lunar, Madison, WI, USA). Phantom Quality Assurance (QA) of the DXA equipment was performed daily. All fractured lumbar vertebrae were excluded, and BMD T-scores at femoral neck and total hip were calculated using the Third National Health and Nutrition Examination Survey with reference data of female Caucasians aged 20-29 years [26]. iNsight software (MediMaps, Geneva, Switzerland) version 3.0.1 was used to calculate TBS values from the DXA scans used for lumbar spine BMD (L1-L4), and fractured vertebrae were excluded. European (Medimaps) reference population was used.

Lateral images of the thoracolumbar spine (T4-L4) were obtained from DXA scans with the patient in a lateral decubitus position with lumbar support and hips flexed 90 degrees. An experienced physician (TTB) performed VFA and grading of the fracture severity using Genant's method for the semiquantitative (SQ) vertebral fracture scoring [27]. This combines the visual identification of fracture of vertebral bodies (height loss of the anterior, middle, posterior, or the whole vertebra) and grading of the fracture by percentage of height loss. A SQ score of 0 (SQ0) $(<20 \%$ height loss) is a non-fractured vertebra, SQ1 (20-25\% height loss) a mild fracture, SQ2 (25-40\% height loss) a moderate fracture, and SQ3 ( $\geq 40 \%$ height loss) a severe fracture. We classified the presence of one or more SQ1, SQ2, or SQ3 fractures as SQ1-SQ3 fractures, one or more SQ2 or SQ3 fractures as SQ2-SQ3 fractures, and presence of at least one SQ3 fracture as $\geq$ SQ3. The inter-observer agreement of SQ1-SQ3 fractures tested against another experienced clinician showed a $\mathrm{K}$ of $0.84(95 \%$ CI $0.70,0.98)$ [23].

\section{Statistical analyses}

Characteristics of the cohort were calculated as mean \pm standard deviation (SD) for the continuous variables and number with percentages $(\%)$ for categorical variables. Continuous variables were checked for normality using quantile-quantile (QQ) plot. All these variables were normally distributed except breastfeeding which was log-transformed in further analyses. Scatterplots were performed between continuous variables and visually checked for linearity. Univariable linear regression analyses were performed to investigate associations between the outcome variable TBS and clinical relevant determinants (age, BMI, history of prior fractures after the age of 50, falls during the last 12 months before inclusion, parental 
history of hip fractures, comorbidities, use of medications, number of children, breastfeeding, currently smoking, daily alcohol consumption, physical activity, consumption of dairy products, prevalence of SQ1-SQ3 fractures, femoral neck and lumbar spine BMD). Only determinants significant at $\mathrm{p}$-level $<0.10$ were retained and included in multivariable models. Multiple linear regression analyses were performed, and because of potential multi-collinearity between TBS, femoral neck, and lumbar spine BMD, we tested different models for each of the traits to explore the attributional variance in the outcome variable by the introduced determinants. Nonsignificant determinants were removed one by one until the exposure variables with statistical significant association remained $(p<0.05)$. Determinants that had been removed were reintroduced one by one to re-check for significance. Results are presented as $\beta$ coefficients with $95 \%$ confidence intervals (CIs), $p$ values, and explained variance $\left(\mathrm{R}^{2}\right)$. The same procedure was performed with femoral neck and lumbar spine BMD as outcome variables. Univariable logistic regression analyses were performed to explore associations between SQ1-SQ3 fractures (yes vs. no) as the outcome variable and the determinants used in the linear regression models (listed above). Variables with significant association at $p$ level $<0.10$ were included in the multivariable logistic regression analyses. We tested different models including TBS, femoral neck, and lumbar spine BMD as determinants to evaluate the association with SQ1-SQ3 fractures. Determinants without significant association with the outcome SQ1-SQ3 fractures were removed one by one until the final model contained only the exposure variables with significant association $(p<0.05)$. Then, the removed variables were reintroduced one by one to re-check for significance. Results are presented by odds ratio (OR) with 95\% CI. Evaluation of the predictive accuracy of the models was assessed by calibration and discrimination. Calibration was evaluated by the Hosmer and Lemeshow goodness-of-fit test. A statistically non-significant Hosmer and Lemeshow result $(p>0.05)$ suggests that the fit of the model is acceptable. Discrimination of SQ1-SQ3 fractures was evaluated by analysis of the area under the receiver operating characteristic (ROC) curve. We defined acceptable discriminatory capability as an area under the ROC curve greater than 0.7. Standardized regression coefficients $\left(\beta_{\text {per SD }}\right)$ or odds ratio $\left(\mathrm{OR}_{\text {per SD }}\right)$ with $95 \% \mathrm{CI}$ was used to facilitate the comparison of the strength of the associations between the continuous exposure variables and the outcome variables. The number of determinants in the multiple linear regression models did not exceed $10 \%$ of the number of observations. The number of determinants in the multiple logistic regression models never exceeded 14, as there were 141 SQ1-SQ3 fractures (maximum 10 events per determinant). All analyses were performed using Stata v15 (Version 15, StataCorp LP, TX, USA).

\section{Results}

The mean age of the 496 women was 65.6 years $( \pm 8.6)$ and $193(42.1 \%)$ women had sustained one or more fractures prior to the index fracture after the age of 50 (Table 1). One in three exhibited SQ1-SQ3 fractures on VFA. Mean TBS was 1.27 and BMD at femoral neck, total hip, and lumbar spine was $0.795 \mathrm{~g} / \mathrm{cm}^{2}, 0.835 \mathrm{~g} / \mathrm{cm}^{2}$, and $1.027 \mathrm{~g} / \mathrm{cm}^{2}$, respectively. The mean number of falls during the last 12 months prior to

Table 1 Characteristics of 496 women 50 years and older with a recent fragility fracture

\begin{tabular}{|c|c|c|}
\hline & Number & Total \\
\hline Age, years & 496 & $65.6 \pm 8.6$ \\
\hline Body mass index, $\mathrm{kg} / \mathrm{m}^{2}$ & 496 & $26.1 \pm 4.0$ \\
\hline History of prior fracture after age of 50 & 459 & $193(42.1)$ \\
\hline Number of falls during the last 12 months & 489 & $1.3 \pm 0.7$ \\
\hline Parental history of hip fracture & 410 & $100(24.4)$ \\
\hline Ulcus/gastritis & 476 & $56(11.8)$ \\
\hline Asthma/COLD & 489 & $53(10.8)$ \\
\hline Type 1 and type 2 diabetes & 495 & $23(4.6)$ \\
\hline Rheumatoid arthritis & 488 & $22(4.5)$ \\
\hline Myocardial infaction & 496 & $13(2.6)$ \\
\hline Cancer & 495 & $71(14.3)$ \\
\hline Hypothyreosis & 490 & $54(11.2)$ \\
\hline Hyperthyreosis & 490 & $13(2.7)$ \\
\hline Use of antacids & 483 & $76(15.7)$ \\
\hline Use of statins & 488 & $119(24.4)$ \\
\hline Use of oral glucocorticoids & 486 & $28(5.8)$ \\
\hline Menopausal estrogen supplementation & 436 & $29(6.7)$ \\
\hline Use of AOD at baseline & 446 & $41(9.2)$ \\
\hline Postmenopausal status & 447 & $429(96.0)$ \\
\hline Age at menopause, years & 399 & $48.7 \pm 4.9$ \\
\hline Number of children & 432 & $2.2 \pm 1.2$ \\
\hline Nullipara & 432 & $34(7.8)$ \\
\hline Breastfeeding, months ${ }^{\mathrm{a}}$ & 325 & $10(0-96)$ \\
\hline No breastfeeding & 325 & $45(13.9)$ \\
\hline Currently smoking & 479 & $71(14.8)$ \\
\hline Daily alcohol intake & 487 & $48(9.8)$ \\
\hline Physical activity, h/week & 454 & $2.8 \pm 1.8$ \\
\hline Intake of dairy products, units/day & 480 & $2.3 \pm 1.1$ \\
\hline Trabecular bone score lumbar spine & 496 & $1.27 \pm 0.10$ \\
\hline SQ1-SQ3 fracture & 423 & $141(33.3)$ \\
\hline Femoral neck BMD, $\mathrm{g} / \mathrm{cm}^{2}$ & 482 & $0.795 \pm 0.105$ \\
\hline Total hip BMD, $\mathrm{g} / \mathrm{cm}^{2}$ & 482 & $0.835 \pm 0.118$ \\
\hline Lumbar spine $\mathrm{BMD}, \mathrm{g} / \mathrm{cm}^{2}$ & 496 & $1.027 \pm 0.166$ \\
\hline Lowest BMD any site, T-score & 496 & $-2.1 \pm 0.9$ \\
\hline
\end{tabular}

$C O L D$ chronic obstructive lung disease, $A O D$ anti-osteoporosis drugs, $S Q$ vertebral fractures assessed by semiquantitative method, $B M D$ bone mineral density

Values are mean $\pm \mathrm{SD}$ or $n(\%)$, except ${ }^{\mathrm{a}}$ median (range) 
inclusion was 1.3 , about one in four women reported a history of parental hip fracture, and one in ten reported daily alcohol intake. The women had on average given birth to 2.2 children (including the $7.8 \%$ of the women who were nulliparous). The median duration of total time of breastfeeding was 10 months (range 0-96 months).

\section{Determinants of TBS}

Higher age $\left(\beta_{\text {per SD }}=-0.26,95 \% \mathrm{CI}-0.36,-0.15\right)$, a history of parental hip fracture $(\beta=-0.29,95 \% \mathrm{CI}-0.54,-0.05)$, and daily alcohol intake (yes vs. no) $(\beta=-0.43,95 \% \mathrm{CI}-$ $0.79,-0.08$ ) were associated with a lower TBS (Table 2; Fig. $1)$. Higher age at menopause $\left(\beta_{\text {per SD }}=0.11,95 \%\right.$ CI 0.01 , $0.21)$, higher BMD of the femoral neck $\left(\beta_{\text {per SD }}=0.34,95 \%\right.$ CI $0.25,0.43)$, and lumbar spine $\left(\beta_{\text {per SD }}=0.40,95 \%\right.$ CI 0.31 , 0.48 ) were associated with higher TBS. In models additionally including SQ1-SQ3 fractures, femoral neck or lumbar spine BMD, age at menopause were no longer associated with TBS. SQ1-SQ3 fractures were not associated with TBS in models including age and daily alcohol consumption. Replacing SQ1-SQ3 fractures with SQ2-SQ3 fractures or SQ3 fractures in multivariable analyses did not change the results. The model including the significant determinant age, parental hip fracture, daily alcohol consumption, number of children, and lumbar spine BMD explained $28 \%$ of the variance in TBS. Femoral neck BMD explained $8 \%$ and lumbar spine BMD $18 \%$ of the variance in TBS.

\section{Determinants of SQ1-SQ3 fractures}

Age $\left(\mathrm{OR}_{\text {per } \mathrm{SD}}=1.94,95 \%\right.$ CI $\left.1.51-2.46\right)$ and a history of prior fractures $(\mathrm{OR}=1.71,95 \% \mathrm{CI} 1.09-2.71)$ were positively associated with SQ1-SQ3 fractures (Table 3). Lumbar spine $\mathrm{BMD}\left(\mathrm{OR}_{\text {per } \mathrm{SD}}=0.7595 \%\right.$ CI $\left.0.60-0.95\right)$ was negatively associated with SQ1-SQ3 fractures in models including age and prior fracture. SQ1-SQ3 fractures were neither associated with TBS nor femoral neck BMD in models including age and prior fractures. In analyses with SQ2-SQ3 fractures and SQ3 fractures as outcome variables, the results were similar.

\section{Determinants of femoral neck BMD}

Higher age $\left(\beta_{\text {per SD }}=-0.35,95 \%\right.$ CI: $\left.-0.43,-0.27\right)$ was associated with lower femoral neck BMD, while higher BMI $\left(\beta_{\text {per SD }}=0.28,95 \%\right.$ CI: $\left.0.20,0.36\right)$ and higher TBS $\left(\beta_{\text {per SD }}=\right.$ $0.32,95 \%$ CI: $0.25,0.40)$ were associated with higher femoral neck BMD (Table 4). Age, BMI, myocardial infarction, and TBS explained $32 \%$ of the variance in femoral neck BMD. TBS explained $10 \%$ of the variance in femoral neck BMD.

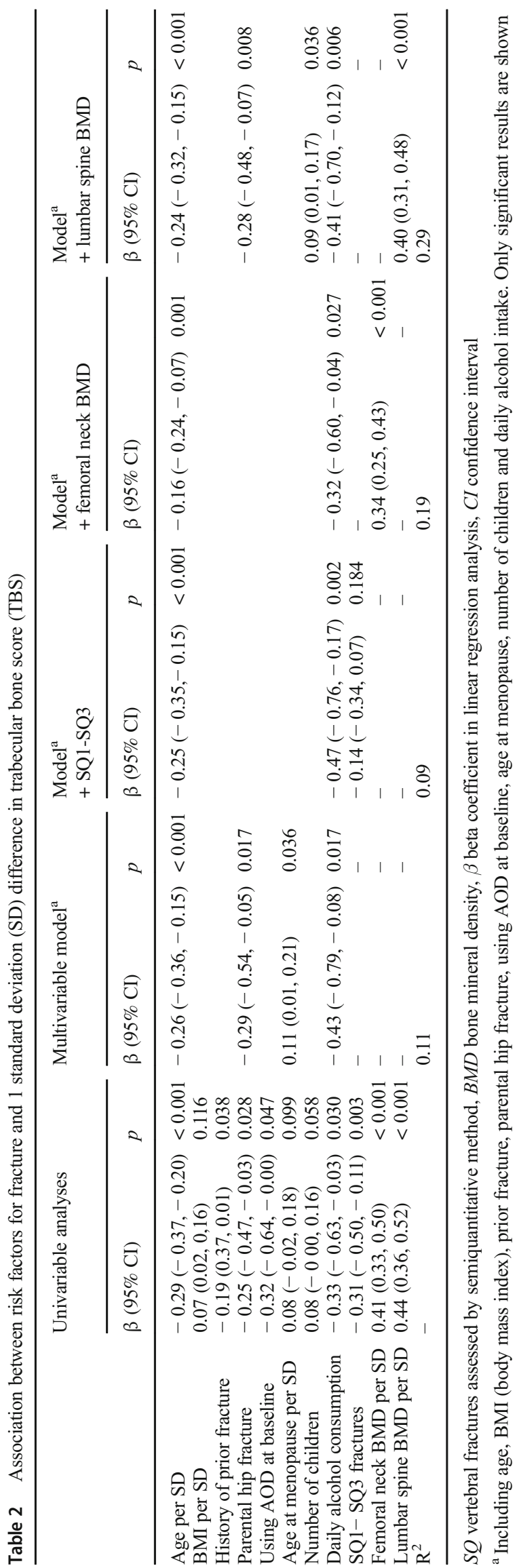


Fig. 1 Associations between femoral neck and lumbar spine bone mineral density (BMD), trabecular bone score (TBS) and vertebral fractures on VFA (SQ1SQ3) with attributed variance of their determinants. BMI body mass index

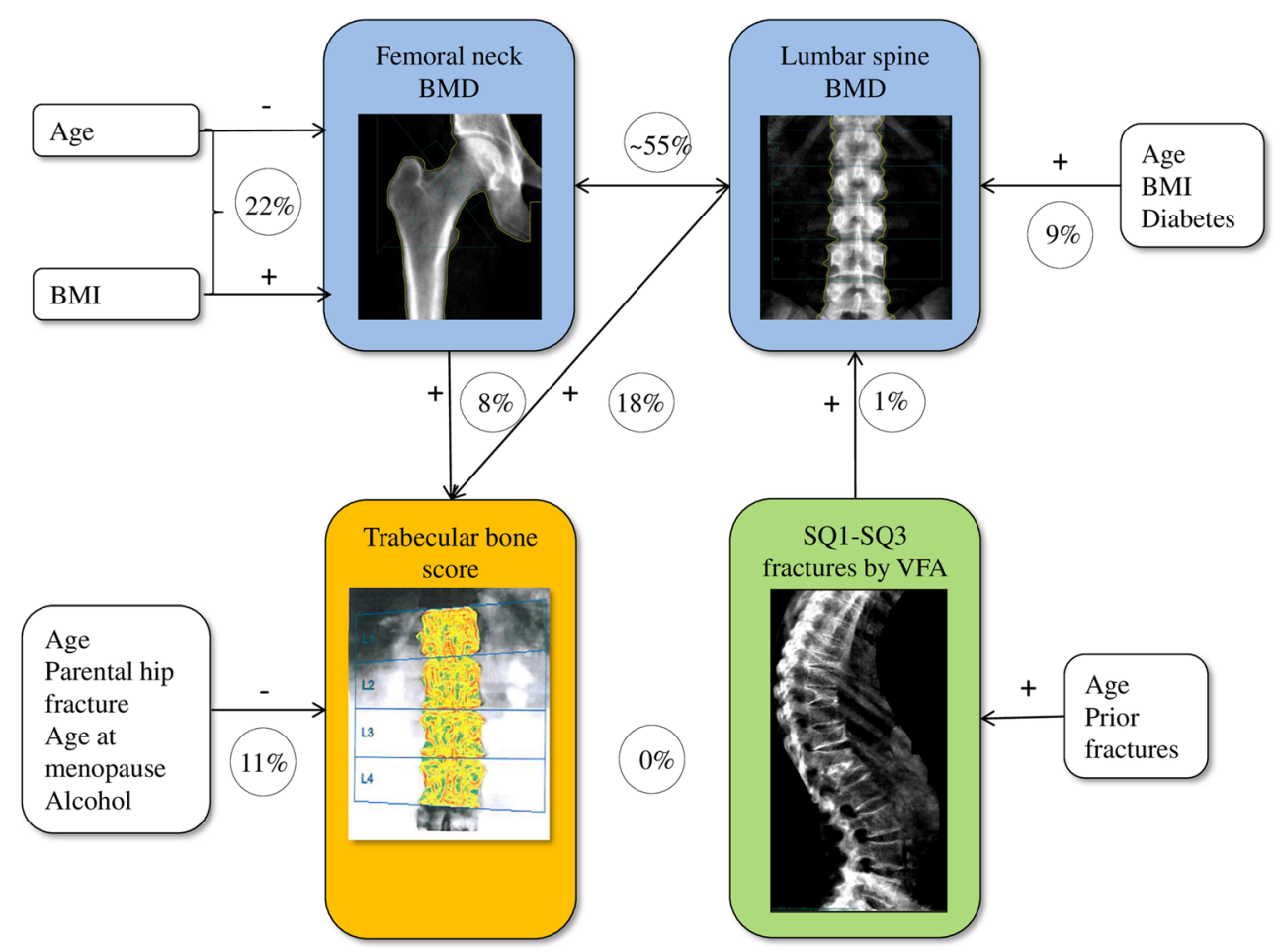

\section{Determinants of lumbar spine BMD}

SQ1-SQ3 fractures $\left(\beta_{\text {per SD }}=-0.25,95 \% \mathrm{CI}-0.43,-0.07\right)$ were associated with a lower lumbar spine BMD, while higher age $\left(\beta_{\text {per SD }}=0.20,95 \% \mathrm{CI} 0.12,0.29\right)$, higher $\mathrm{BMI}\left(\beta_{\text {per SD }}=\right.$ $0.20,95 \%$ CI $0.12,0.29)$, diabetes ( $\beta=0.61,95 \%$ CI: 0.21 , $1.00)$ and high TBS ( $\beta_{\text {per SD }}=0.43,95 \%$ CI $\left.0.34,0.51\right)$ were associated with higher lumbar spine BMD (Table 5). TBS and SQ1-SQ3 fractures explained $17 \%$ and $1 \%$ of the variance in lumbar spine BMD, respectively.

\section{Discussion}

No association between TBS and SQ1-SQ3 fractures could be demonstrated in this cohort of women with prevalent fragility fractures. We found that higher age, a history of parental hip fracture, and daily alcohol consumption were associated with lower TBS, while higher femoral neck and lumbar spine BMD were associated with higher TBS. Age and prior fractures were positively associated with SQ1-SQ3 fractures, whereas lumbar spine BMDs were negatively associated with SQ1SQ3 fractures.

The unexpected finding of no association between TBS and SQ1-SQ3 fractures has previously been shown in a study of elderly Swedish women with prevalent vertebral fractures [20] and in men in the Manitoba study and MrOs study with incident vertebral fractures $[21,22]$. There are other studies showing an association between TBS and SQ1-SQ3 fractures in women $[18,19]$. We do not know why these findings diverge between studies, but several factors may be of importance. Firstly, genetic factors explain a large part of the variation in TBS and vertebral fractures, and genetic factors may vary significantly between countries and the cohorts studied. Scandinavian women are a genetically homogenous group, and they have the highest prevalence of vertebral fractures in Europe [28]. Secondly, TBS is derived from the same images as lumbar spine BMD. Lumbar spine BMD accounted for a larger contribution to the variance of TBS $(20 \%)$ than femoral neck BMD (10\%) in our cohort. SQ1-SQ3 fractures were negatively associated with lumbar spine BMD, and only about $1 \%$ of the variance in lumbar spine BMD was explained by SQ1-SQ3 fractures, suggesting a weak association. No association between SQ1-SQ3 fractures and femoral neck BMD was found. We might infer that in our cohort of women with fragility fractures, SQ1-SQ3 fractures reflect reduced bone strength that is not captured by BMD nor TBS.

The determinants of TBS identified in our study differ somewhat from what was found in the population-based Canadian Manitoba study [10]. We found a negative association of TBS with age and daily alcohol intake, but no associations with BMI, glucocorticoid use, rheumatoid arthritis, or chronic obstructive pulmonary disease. This could be due to the smaller sample size in our study compared to the Manitoba study $(496$ vs. 29,407) or that the source of the data differed. We collected self-reported information on lifestyle, comorbidities, and medication, with limitations regarding self-reported data (i.e. possible information bias). In the Manitoba study, this information was retrieved from register-based data of physician billing claims, hospital discharge abstracts, and 

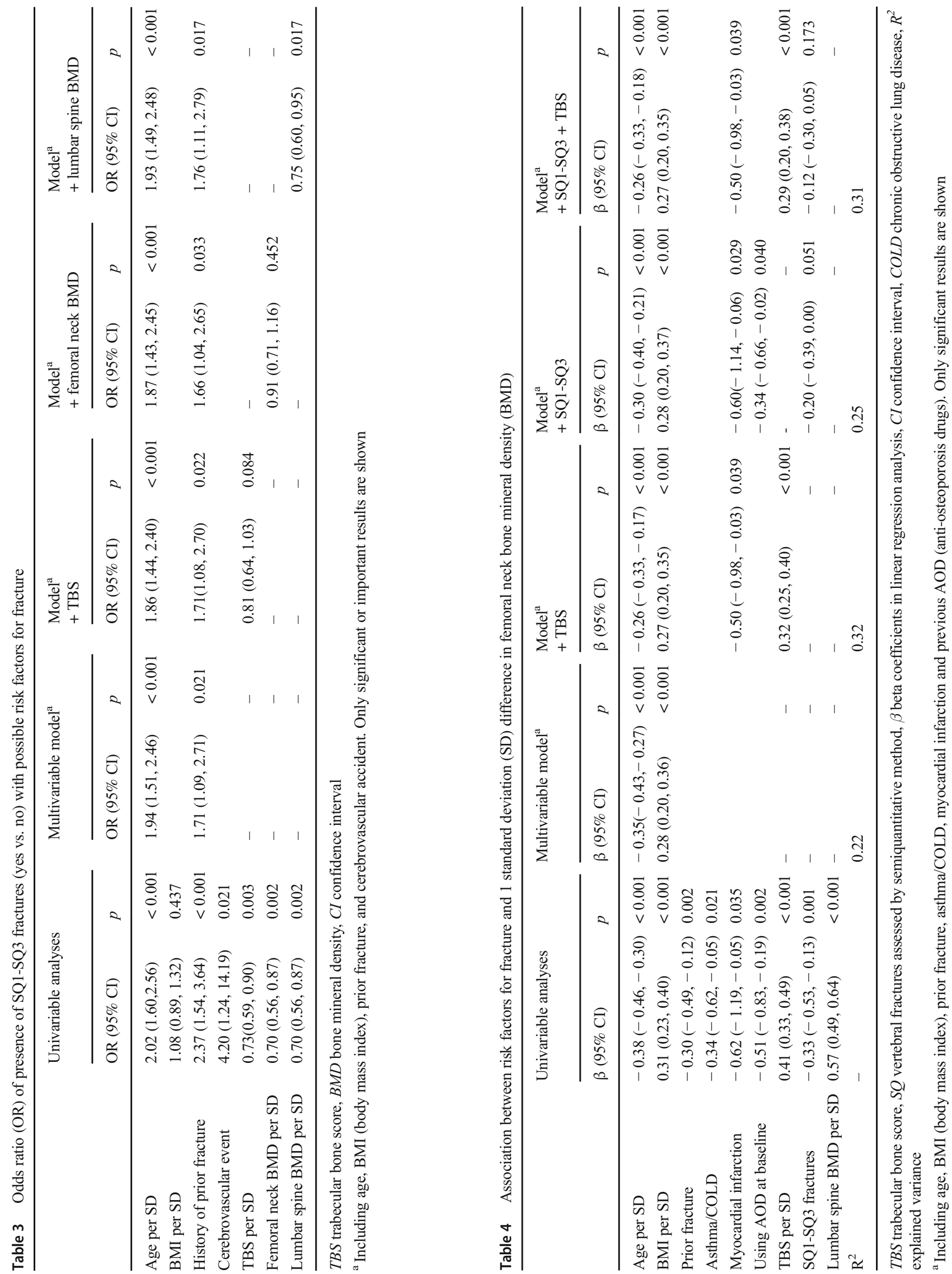
provincal retail pharmacy database, with uncertainities regarding the validity of registered information (i.e. whether the discharge record reflects the disease at hand). Both studies reported a positive association between femoral neck and lumbar spine BMD and TBS. The variance in TBS explained by femoral neck and lumbar spine BMD in the Manitoba women was $7 \%$ and $11 \%$, respectively, compared to $20 \%$ and $28 \%$ in the NoFRACT women. This might be explained by the inclusion of healthier subjects in the Manitoba cohort where only $14 \%$ had a previous major fracture, compared to the NoFRACT cohort, where all the women had a clinical fragility fracture. In addition, patients with BMI $>37 \mathrm{~kg} / \mathrm{m}^{2}$ were not excluded in the Manitoba study, which may have diluted the association between BMD and TBS.

We found higher OR for SQ1-SQ3 fractures in patients with a history of a prior fracture, increasing age and decreasing lumbar spine BMD, in line with other studies [29-31]. No association between SQ1-SQ3 fractures and body weight or BMI was found in adjusted models, which is in accordance with some studies [29-31], but contrary to others [32, 33]. Studies on incident vertebral fractures, however, show similar results. In the EPOS study, including 3402 women, late menarche (after 16 years of age) was associated with an increased risk of incident vertebral fracture, whereas HRT, increasing body weight, and BMI were protective [16]. Lifestyle factors such as smoking, alcohol intake, physical activity, or milk consumption showed no association with incident vertebral fractures, in line with our findings in patients with prevalent vertebral fractures. In the prospective population-based Rotterdam Study including 2467 women, age, low BMD, prevalent vertebral fractures, early menopause $(<45$ years of age), currently smoking, and walking aid use were associated with incident vertebral fractures in women [15]. Prevalent and incident vertebral fractures are not comparable, although the risk factors should be similar.

To the best of our knowledge, this is the first study on determinants of TBS in a cohort of women with fragility fractures. However, there are some limitations. The study sample was perhaps too small to show associations with the main outcome variables (TBS, SQ1-SQ3 fractures) and certain risk factors, such as glucocorticoid use, rheumatoid arthritis, and chronic obstructive pulmonary disease. On the other hand, we showed that more of the variance in TBS could be explained by BMD than in the Manitoba study, maybe due to exclusion of obese patients or the selection of patients who all had suffered at least one fragility fracture. As a result of the crosssectional design, it was not possible to determine the temporal nature of any observed associations.

In conclusion, no statistical significant association between TBS and SQ1-SQ3 fractures was found. Higher age, a history of parental hip fracture, and daily alcohol consumption were associated with lower TBS, while higher femoral neck and lumbar spine BMD were associated with higher TBS. Age 
and a history of prior fractures were positively associated with SQ1-SQ3 fractures, while lumbar spine BMD was negatively associated with SQ1-SQ3 fractures. Modifiable risk factors such as daily alcohol intake and low BMD are important targets in fracture prevention strategies. Since TBS and SQ1SQ3 fractures are not associated, each of them may act as independent risk factors for fracture, justifying the use of both in post-fracture risk assessment.

Funding information This work was funded by The Regional Health Authorities (243852), The North Norwegian Health Authorities (14083), and Vestre Viken Hospital Trust (1903007). They had no role in the design or conduct of the study; in the collection, analyses, and interpretation of the data; or in the preparation, review, or approval of the manuscript. Hanne Louise Hoelstad at Drammen Hospital and Marit Osima, Anita Kanniainen, and May Greta Pedersen at the Clinical Research Unit, University Hospital of North Norway, recruited patients, obtained consents and questionnaires, and performed DXA scans. MediMaps provided temporary license to analyze trabecular bone score (TBS) and Pål Wangen, Scanex, helped with calibration of TBS.

Compliance with ethical standards The study was approved by The Regional Committee for Medical and Health Research Ethics (REK 2014/2260).

Conflicts of interest Tove T Borgen, Åshild Bjørnerem, Camilla Andreasen, Cathrine Brunborg, Lars M Hübschle, Ellen M Apalset, Jan-Erik Gjertsen, Trude Basso, Ida Lund, Ann Kristin Hansen, and Cecilie Dahl declare that they have no conflict of interest. Lene B Solberg has received speaker honorarium from Eli Lilly. May-Britt Stenbro has received speaker fees from Eli Lilly, Amgen, and Takeda. Wender Figved has received speaker fees from Ortomedic AS. JensMeinhard Stutzer has received grants for educational activities from BSN Medical. Lars Nordsletten has received speaker fees from Novartis, Eli Lilly, and Ortomedic AS. Frede Frihagen has received grants for educational activities from Eli Lilly, Amgen, and Takeda. Erik F Eriksen has received speaker fees from Novartis, Eli Lilly, Amgen, MSD, EffRx, IDS, and Shire.

Open Access This article is distributed under the terms of the Creative Commons Attribution-NonCommercial 4.0 International License (http:// creativecommons.org/licenses/by-nc/4.0/), which permits any noncommercial use, distribution, and reproduction in any medium, provided you give appropriate credit to the original author(s) and the source, provide a link to the Creative Commons license, and indicate if changes were made.

\section{References}

1. Kanis JA, Cooper C, Rizzoli R, Reginster JY, Scientific Advisory Board of the European Society for C, Economic Aspects of O, the Committees of Scientific A, National Societies of the International Osteoporosis F (2019) European guidance for the diagnosis and management of osteoporosis in postmenopausal women. Osteoporos Int 30:3-44

2. Silva BC, Broy SB, Boutroy S, Schousboe JT, Shepherd JA, Leslie WD (2015) Fracture risk prediction by non-BMD DXA measures: the 2015 ISCD Official Positions Part 2: Trabecular Bone Score. J Clin Densitom 18:309-330
3. Rosen HN, Vokes TJ, Malabanan AO, Deal CL, Alele JD, Olenginski TP, Schousboe JT (2013) The Official Positions of the International Society for Clinical Densitometry: vertebral fracture assessment. J Clin Densitom 16:482-488

4. Martineau P, Leslie WD (2017) Trabecular bone score (TBS): method and applications. Bone 104:66-72

5. Silva BC, Leslie WD (2017) Trabecular bone score: a new DXAderived measurement for fracture risk assessment. Endocrinol Metab Clin N Am 46:153-180

6. Popp AW, Meer S, Krieg MA, Perrelet R, Hans D, Lippuner K (2016) Bone mineral density (BMD) and vertebral trabecular bone score (TBS) for the identification of elderly women at high risk for fracture: the SEMOF cohort study. Eur Spine J 25:3432-3438

7. Harvey NC, Gluer CC, Binkley N et al (2015) Trabecular bone score (TBS) as a new complementary approach for osteoporosis evaluation in clinical practice. Bone 78:216-224

8. Schousboe JT, Vo T, Taylor BC et al (2016) Prediction of Incident major osteoporotic and hip fractures by trabecular bone score (TBS) and prevalent radiographic vertebral fracture in older men. J Bone Miner Res 31:690-697

9. McCloskey EV, Oden A, Harvey NC et al (2016) A meta-analysis of trabecular bone score in fracture risk prediction and its relationship to FRAX. J Bone Miner Res 31:940-948

10. Leslie WD, Krieg MA, Hans D, Manitoba Bone Density P (2013) Clinical factors associated with trabecular bone score. J Clin Densitom 16:374-379

11. Ho-Pham LT, Hans D, Doan MC, Mai LD, Nguyen TV (2016) Genetic determinant of trabecular bone score (TBS) and bone mineral density: a bivariate analysis. Bone 92:79-84

12. Chen P, Krege JH, Adachi JD et al (2009) Vertebral fracture status and the World Health Organization risk factors for predicting osteoporotic fracture risk. J Bone Miner Res 24:495-502

13. Åkesson K, Marsh D, Mitchell PJ, AR ML, Stenmark J, Pierroz DD, Kyer C, Cooper C, Group IOFFW (2013) Capture the fracture: a best practice framework and global campaign to break the fragility fracture cycle. Osteoporos Int 24:2135-2152

14. Schousboe JT (2016) Epidemiology of vertebral fractures. J Clin Densitom 19:8-22

15. van der Klift M, de Laet CE, McCloskey EV, Johnell O, Kanis JA, Hofman A, Pols HA (2004) Risk factors for incident vertebral fractures in men and women: the Rotterdam Study. J Bone Miner Res 19:1172-1180

16. Roy DK, O'Neill TW, Finn JD, Lunt M, Silman AJ, Felsenberg D, Armbrecht G, Banzer D, Benevolenskaya LI, Bhalla A, Bruges Armas J, Cannata JB, Cooper C, Dequeker J, Diaz MN, Eastell R, Yershova OB, Felsch B, Gowin W, Havelka S, Hoszowski K, Ismail AA, Jajic I, Janott I, Johnell O, Kanis JA, Kragl G, Lopez Vaz A, Lorenc R, Lyritis G, Masaryk P, Matthis C, Miazgowski T, Gennari C, Pols HA, Poor G, Raspe HH, Reid DM, Reisinger W, Scheidt-Nave C, Stepan JJ, Todd CJ, Weber K, Woolf AD, Reeve J, European Prospective Osteoporosis Study (EPOS) (2003) Determinants of incident vertebral fracture in men and women: results from the European Prospective Osteoporosis Study (EPOS). Osteoporos Int 14:19-26

17. Liu CT, Karasik D, Zhou Y, Hsu YH, Genant HK, Broe KE, Lang TF, Samelson EJ, Demissie S, Bouxsein ML, Cupples LA, Kiel DP (2012) Heritability of prevalent vertebral fracture and volumetric bone mineral density and geometry at the lumbar spine in three generations of the Framingham study. J Bone Miner Res 27:954-958

18. Iki M, Tamaki J, Kadowaki E, Sato Y, Dongmei N, Winzenrieth R, Kagamimori S, Kagawa Y, Yoneshima H (2014) Trabecular bone score (TBS) predicts vertebral fractures in Japanese women over 10 years independently of bone density and prevalent vertebral deformity: the Japanese Population-Based Osteoporosis (JPOS) cohort study. J Bone Miner Res 29:399-407 
19. Nassar K, Paternotte S, Kolta S, Fechtenbaum J, Roux C, Briot K (2014) Added value of trabecular bone score over bone mineral density for identification of vertebral fractures in patients with areal bone mineral density in the non-osteoporotic range. Osteoporos Int $25: 243-249$

20. Johansson L, Sundh D, Zoulakis M, Rudang R, Darelid A, Brisby H, Nilsson AG, Mellstrom D, Lorentzon M (2018) The prevalence of vertebral fractures is associated with reduced hip bone density and inferior peripheral appendicular volumetric bone density and structure in older women. J Bone Miner Res 33:250-260

21. Hans D, Goertzen AL, Krieg MA, Leslie WD (2011) Bone microarchitecture assessed by TBS predicts osteoporotic fractures independent of bone density: the Manitoba study. J Bone Miner Res 26:2762-2769

22. Schousboe JT, Vo TN, Langsetmo L et al (2017) Association of Trabecular Bone Score (TBS) with incident clinical and radiographic vertebral fractures adjusted for lumbar spine BMD in older men: a prospective cohort study. J Bone Miner Res 32:1554-1558

23. Borgen TT, Bjørnerem A, Solberg LB et al (2019) High prevalence of vertebral fractures and low trabecular bone score in patients with fragility fractures: a cross-sectional sub-study of NoFRACT. Bone 122:14-21

24. Andreasen C, Solberg LB, Basso T et al (2018) Effect of a fracture liaison service on the rate of subsequent fracture among patients with a fragility fracture in the Norwegian capture the fracture initiative (NoFRACT): a trial protocol. JAMA Netw Open 1:e185701

25. Borgen TT, Bjørnerem A, Solberg LB et al (2019) Post-fracture risk assessment: target central sited fractures first! A sub-study of NoFRACT. J Bone Miner Res 34:2036-2044

26. Kanis JA, Adachi JD, Cooper C, Clark P, Cummings SR, DiazCuriel M, Harvey N, Hiligsmann M, Papaioannou A, Pierroz DD, Silverman SL, Szulc P, Epidemiology and Quality of Life Working Group of IOF (2013) Standardising the descriptive epidemiology of osteoporosis: recommendations from the Epidemiology and Quality of Life Working Group of IOF. Osteoporos Int 24:2763-2764
27. Genant HK, Wu CY, van Kuijk C, Nevitt MC (1993) Vertebral fracture assessment using a semiquantitative technique. J Bone Miner Res 8:1137-1148

28. O'Neill TW, Felsenberg D, Varlow J, Cooper C, Kanis JA, Silman AJ (1996) The prevalence of vertebral deformity in european men and women: the European Vertebral Osteoporosis Study. J Bone Miner Res 11:1010-1018

29. Schousboe JT, Rosen HR, Vokes TJ, Cauley JA, Cummings SR, Nevitt M, Black DM, Orwoll ES, Kado DM, Ensrud KE, Study of Osteoporotic Fractures Research Group (2014) Prediction models of prevalent radiographic vertebral fractures among older women. J Clin Densitom 17:378-385

30. Vogt TM, Ross PD, Palermo L, Musliner T, Genant HK, Black D, Thompson DE (2000) Vertebral fracture prevalence among women screened for the Fracture Intervention Trial and a simple clinical tool to screen for undiagnosed vertebral fractures. Fracture Intervention Trial Research Group. Mayo Clin Proc 75:888-896

31. Kaptoge S, Armbrecht G, Felsenberg D, Lunt M, O'Neill TW, Silman AJ, Reeve J, Group ES (2004) When should the doctor order a spine X-ray? Identifying vertebral fractures for osteoporosis care: results from the European Prospective Osteoporosis Study (EPOS). J Bone Miner Res 19:1982-1993

32. Ling X, Cummings SR, Mingwei Q, Xihe Z, Xioashu C, Nevitt M, Stone K (2000) Vertebral fractures in Beijing, China: the Beijing Osteoporosis Project. J Bone Miner Res 15:2019-2025

33. Middleton ET, Gardiner ED, Steel SA (2009) Which women should be selected for vertebral fracture assessment? Comparing different methods of targeting VFA. Calcif Tissue Int 85:203-210

Publisher's note Springer Nature remains neutral with regard to jurisdictional claims in published maps and institutional affiliations. 